\title{
Infratentorial and Spinal Cord Ependymal Tumor
}

National Cancer Institute

\section{Source}

National Cancer Institute. Infratentorial and Spinal Cord Ependymal Tumor. NCI

Thesaurus. Code C131613.

An ependymal tumor affecting the infratentorial region of the brain and the spinal cord. 